\title{
EDITORIAL
}

\section{OLD GUYS SAY YES TO COMMUNITY}

This issue of Studies in Adult Education and Learning features five contributions that are the result of three years of research carried out by the partners of the Old Guys Say Yes to Community project. ${ }^{1}$ In Slovenia, Estonia, Poland and Portugal, partners used similar starting points to study the low participation rates of older men in educational and learning programmes as well as in the community. Applying similar guidelines to research these phenomena, we carried out the following activities: first, we sought out the best practices in our countries relating to the informal learning of older adults in the community, focusing on older men. The main aim was to gain some insight into the real situation of men's learning in the community. Second, we carried out an in-depth investigation. Each partner interviewed a sample of 90-100 men aged 60 years or more in selected communities. In addition, focus-group debates were organised in these communities, which included local decision makers and members of civil society organisations. The project's organisational team prepared scripts for the semi-structured interviews and focus groups. Nevertheless, each partner had some freedom to adapt the research instruments according to local contexts if necessary.

An interim report was drawn up and based on the findings, the partners worked on their recommendations. These targeted national and local authorities as well as civil society organisations. We tried to gain as much constructive feedback as possible and include it in our work. We also analysed the differences that had appeared between our countries. Based on the reports, evaluations and analyses, we created a toolkit adapted to other EU contexts and developed a blended learning programme. The latter was tested by some NGO representatives from Slovenia within a 4-week e-learning programme. Based on their reflections and an evaluation of the complet e-learning programme, we adapted the programme so that it can be used by the partners. Last but not least, we used all of our work and findings to compile an open educational resource-based portal, which will serve the wider public, and presented it at the final conference which took place under the

1 This project has been funded with support from the European Commission. This publication only reflects the views of the authors, and the Commission cannot be held responsible for any use which may be made of the information contained herein. Details about the project: Erasmus+, Strategic Partnership for Adult Education, agreement number 16-KA204-021604, case number KA2-AE-9/16. The lead organisation was the University of Ljubljana; the partner organisations were the Slovenian Association of Adult Educators, the University of Algarve, the University of Wrocław, Tallinn University and the Association of Estonian Adult Educators - ANDRAS. 
umbrella of the ESREA Research Network on Education and Learning of Older Adults (ELOA) in Ljubljana on $11^{\text {th }}$ May 2019.

It is widely recognised that learning is influenced by many variables, such as educational background, gender, income level, geographical isolation, digital literacy, foreign language proficiency, etc. In the Old Guys project, we wanted to understand the patterns that emerge when analysing learning according to gender, local contexts and historical practices. In fact, statistical data shows that male participation in adult educational programmes in all partner countries (except Estonia) is lower than female participation. In Poland, it is even decidedly below the EU average for male and female genders (Eurostat, 2017). Moreover, we found that men's participation in adult education is showing a slower increase on average than women's participation, including at EU level (ibid.). As was the case in some past studies (Golding, Mark, \& Foley, 2014), the partners of this project discovered that men are becoming minority participants in certain spaces and sectors of education, and that various national provisions, policies, and structural conditions of the population make it difficult to provide homogeneous explanations of this fact. Nevertheless, we examined the different causes of this issue in our own countries and in a variety of contexts, and searched for explanations that could provide some practical recommendations to the communities. The goal of the Old Guys project was thus to consider society and the role that men's learning can play in it more closely. This task was not chosen randomly: we considered numerous international studies as well as several previous studies carried out by the project team.

One of the few recent books dedicated to men's learning brings together exploratory research work from the United Kingdom, Ireland, Portugal, Greece, China, Australia and New Zealand. An important conclusion to be emphasised from these exploratory accounts was, precisely, that informal learning based in the community was very effective for men:

The research we have analysed shows that, almost counter-intuitively, the most effective learning for most men with limited prior experiences of learning is informal, local, and community-based, which builds on what men know, can do, and are interested in. Learning for such men is less effective if it assumes that all men have a problem, that particular masculinities are the problem, or if it requires them to be served up curricula and assessments for qualifications, vocational training or literacy, as students, customers, clients, or patients, which presupposes a deficit (Golding, Mark, \& Foley, 2014, pp. 256-257).

Previous research in Australia (Golding, 2011; 2012) also showed that fostering learning among older men, especially those with high levels of illiteracy, could make a difference in various dimensions of their lives, positively affecting their well-being - namely their physical and mental health. Moreover, informal learning taking place informally in the community generated a huge social movement (the men's shed movement) in Australia that has similarities to more recent movements in a few European countries. 
Previous exploratory research conducted in Slovenia, Estonia, Malta and Portugal (Jelenc Krašovec \& Radovan, 2014) revealed some promising results. In these countries, there is a big diversity of informal, non-structured spaces where older men feel secure and where various activities had a direct and indirect influence on their well-being. These diverse learning spaces constitute symbolic spaces that frame people's sense of belonging, one built from symbols that have powerful meanings in the community (Kurantowicz, 2008). Illustrative examples of this statement can be found in Slovenia (Jelenc Krašovec, Radovan, Močilnikar, \& Šegula, 2014), Estonia (Tambaum \& Kuusk, 2014), Malta (Galea \& Farrugia-Bonello, 2014), and Portugal (Ricardo, Tavares, Coelho, Lopes, \& Fragoso, 2014). For us it becomes clear that the informal spaces where men interact have the ability to build a sense of belonging that ties them to the community and allows older men to positively contribute to their communities in some way. It is within these symbolic, informal spaces in the community that the importance of socialising appears to be crucial for older men. This is coherent with McGivney's (1999) claims that education is especially successful when it takes place in informal community spaces. Interacting socially is a way to fight back the natural, progressive deterioration of social networks generally associated with ageing. It can also prevent isolation and loneliness that can, associated with other factors, eventually reduce men's well-being.

An important finding of the previous research we had done in these countries refers to the activities and types of informal learning older men prefer (Jelenc Krašovec \& Radovan, 2014). Our conclusions show that men tend to choose hands-on activities, problem-oriented activities in some cases, and those characterised by competition in others (either sports or simple games like dominoes or cards).

However, in many instances, what the case studies unearthed was an informal, situated, community-based and non-structured form of learning, millions of miles away from the rigid structures involving formal learning and vocational training that increasingly crowd in and create extra pressure on professional life. The informal learning style preferred by men is also deeply embedded in their own past and present experience, independent of the source of such experiential knowledge (stemming from work and working life, or roughly coming from leisure) (Fragoso \& Formosa, 2014, p. 103).

We also know that the processes of ageing inevitably bring some social, physical and mental decay across time. Socialising, as we have stressed, is of outmost importance. We know that it is common that ageing brings with it the collapse of social networks and the progressive diminishment of intergenerational contacts (Salgueiro \& Lopes, 2010). Nevertheless, even or especially in these cases, maintaining community ties and networks is still the best answer to the older citizens' situation:

For older adults - more so than for other social groups - the community level is of importance for their social life, when mobility decreases in later life. When 
the radius of action becomes more limited also in a geographic sense, the local surrounding gets more and more important and becomes the most important resource of areas of action, learning opportunities, and intergenerational encounters (Formosa, Jelenc Krašovec, \& Schmidt-Hertha, 2015, pp. 207-208).

Much depends not only on the way that older men make the transition to retirement, but also on their capacity of adapting to retirement. The transition to retirement is a process embedded in a number of overlapping contexts (Grenier, 2012), which force us to give special attention to a number of factors. It implies a loss of old social roles and their gradual replacement with new ones (Smeaton, Barnes, \& Vegeris 2016). It depends on the subjective perceptions of how older citizens look at retirement, on their adaptive capacity and on how the potential states of vulnerability interfere with the ageing processes (Loureiro, Ângelo, Silva, \& Pedreiro, 2015). Transition can therefore mean a path towards social isolation and individual progressive devaluing (Quaresma, 2007). On the other hand, numerous factors might contribute to a positive transition to retirement and to the agentic capacity of individuals to rebuild their social roles. Being active, socialising, and learning in the community are ways to promote the well-being of older citizens. The contributions in this issue of Studies in Adult Education and Learning discuss all of these aspects.

The analysis of the best practices which were selected in the Old Guys project revealed some interesting common patterns. However, due to the wide variety of national and local contexts, a comparative analysis was not possible. More than in segregated male communities, men engaged in various contexts that prioritised practical and informal activities which were often linked to their past professional activities. We also have to pay attention to contexts and meanings. In the case of Portugal, it is very common to find examples of environments in the community where men are predominant. To mention just a few: pigeon clubs, volunteer fire brigades, clubs for hunters and fishermen, pétanque clubs, among others. However, we cannot separate the fact from its historical and cultural origin. Very traditional divisions of gender roles, especially in rural areas, conducted the men towards the domination of public spaces as natural spaces of leisure. At the same time, women were constrained in their use of public space, condemned to live mainly in the private space of the household or rural small property. Furthermore, this leads us to the conclusion that it is very important to understand sociocultural contexts (the symbolic capital of a community, the identity of a community, etc.) because cultural characteristics and historical backgrounds create environments in which the focus on opportunities for older adults (also at the institutional level) is the norm and not the exception.

Our project focused on the careful study of the community, on the social mechanisms around the community as well as on the connection between the community, informal learning and the well-being of older men. Besides the transformation in communities and learning environments, we were also interested in the transformation of individuals. The motives of older men for participating in volunteer activities show they seek them 
out mainly for socialisation. As educators, we often think this is not enough. Rather it is fundamental to anchor older men in the community, to keep their sense of belonging alive. Socialisation prevents isolation and tackles the shrinking of social networks. It is the base for building a community. Only in a community can citizens have the (learning) opportunities to improve their lives. All partners have revealed the importance of informal learning practices for older men. Through the involvement in volunteer associations, as members of the board, or just as associates or participants, older men maintain contact with their peers and younger people. Associations and workplaces are described as privileged spaces of socialisation, where older men can gather, play games or just talk about their past and present lives. This dimension seems to be of huge importance since this feature is referred to in all the partner countries. The associations or the gathering of men in the workplace intentionally or unintentionally provide learning or intergenerational opportunities, which are mostly informal.

What have we learned from the project? Comparative analysis is always very hard to make. Our four countries are very different from each other and include a diversity of contexts within. That being so, our task was to call attention to some general patterns without compromising the identity of each national research. National interpretations, conclusions, and recommendations will always be valid on their own internal merits and capable of being applied in national or local settings. Comparisons, in this case, were to call on commonalities when they exist, point to striking differences when useful, and are an important opportunity for critical reflection.

To this end, we identified four comprehensive topics which have up to now been given insufficient expert attention in the context of our countries: a) Pluralisation of transitions to retirement and ageing; b) Absent bodies and invisible lives; c) Hegemonic masculinities and gendered experiences; and d) Community-based learning, action and spaces. We also defined a series of subtopics which deserve further consideration both within the civil society sector and at the level of national authorities. These include especially 'silver productivity and ageing', 'post work lives and identities independent of paid work', 'ageing (men's) health-related behaviours', 'men's vulnerability in old age', 'men's mental health', 'incomplete script for performing masculinity in later life', 're-defining gender capital in later life', among others.

As the topic titles suggest, we discovered that the barriers to men's participation in learning are numerous, diverse, multidimensional and partially emerging from context specificities. A list of all the barriers identified by partner organisations is now publicly available $^{2}$ but broader generalisation of this data would probably not be constructive. We do not expect, for example, that older men living in poverty and having difficulties even surviving with some dignity would have the necessary conditions to look for opportunities of learning in the community - taking for granted that they exist with some visibility

2 The national recommendations for local authorities and NGOs are published at: https://oldguys.si/recommendation-letters/ and the toolkit at https://oldguys.si/toolkit/. 
in traditional forms accessible to these men. Frequently mentioned barriers that stay out of men's control include, for example:

- low incomes / unemployment / severe financial problems;

- the scarcity of informal learning offers / public spaces for gathering in the community;

- health problems, especially mental problems (dementia, etc.);

- mobility and difficulties in access to public transportation;

- social-geographic isolation and loneliness.

One could eventually say that other barriers to men's participation are somehow attitudinal or can at least be tackled more easily. The shrinking of social networks is not irreversible; the communication capacity can be learnt and developed; older men can learn more about ICT and suddenly begin to have immediate access to a new digital world and information on activities and learning; the willingness to participate can, in theory, depend on simple individual motives. All this is valid. There are, however, two problems when thinking about attitudinal barriers: the first is the circularity that learning presents in its causes and effects. For example, learning can foster participation; but participation requires learning and this fact can hinder men from learning in the first place. We have to understand what the trigger is to unlock some of these situations. The second problem is that we would have to assume that individual attitudes and choices are not determined by a set of inter-related, inter-subjective factors that go beyond the sphere of 'individual choice'.

It is also important to consider that some barriers the partners identified are very particular to a specific context, so we will not mention them here. But this does not mean they are unimportant. Barriers to participation, on the contrary, are the basis for local recommendations to civil society organisations and local power administration. They give us all something to work with and try to solve certain problems. In these conditions, what is truly remarkable is that our four countries are equal when it comes to the dominant forms of learning - and the relative absence of the remaining forms. The evolution in education; the expansion of formal education and the consequent diminishment of value given to informal learning; marketisation and commodification as increasing tendencies in most European countries... all of this and much more can explain the similitudes of what can be dominantly 'offered as learning'.

To conclude, we did find patterns of activities and cooperation in communities that differ between men and women; what is more, those patterns were presented through similar statements in different countries. Men are portrayed as lazy, more passive, preferring to stay at home, reluctant to cooperate, while women are depicted as assertive, active, always prepared to cooperate, etc. However, as andragogues, sociologists, and researchers, of course, we do not believe that these patterns express a 'biological deficit' that men possess or a 'biological advantage' that evolution has granted to women only. On the contrary, such patterns reflect the production and reproduction of gender, gender experiences and practices, which acquire different meanings and characteristics in later life compared to earlier life. Many other categories would better explain the occurrence of the same patterns in the four countries. Our introduction in this editorial has already provided 
some explanations: men and women prefer different activities and types of learning. If the possibilities and conditions for hands-on practical activity, informal and with minimal structure are available, men will participate more. Whenever and wherever learning is more structured, planned, organised, women will participate more.

This bigger expression of women's social activity - or the minor expression of socially active men - no doubt has roots in inequality patterns, which are very common in Europe's past. We can notice that traditional gender roles are very similar in all four countries. They were based on male dominance, a profound asymmetry between the daily tasks of men and women, a full dominance of the labour markets by men, etc. The feminist movement emerged only about forty years ago. Education, and more precisely formal education, was a battle women had to win gradually. Generations of women across Europe saw education as an instrument (among others) of social mobility and the struggle against male domination. But even today, as we speak, this battle is not over. The labour market is still unfair and unequal, with barriers preventing women from getting to the top positions in the labour market and earning equal salaries, and women still fighting stereotypes that associate motherhood with low productivity, etc., without giving up their femininity. This means that qualifications, especially tertiary qualifications, are still crucial for women. Higher education is gradually more frequently attended by women than men. The fact that women are increasingly performing better than men in higher education allows for the speculation that generations of women across Europe still live formal education differently. And if socialised under these dominant perceptions, then it is only natural that they participate more when learning is formal and structured.

The five contributions we find in this special issue discuss specific aspects of the main preoccupations of the Old Guys project. The contributions do not exhaust our findings and we will continue to try to publish our results. Moreover, we are aware of the limitations of the project and the need to continue our research efforts in the years to come. Our final comment thus goes out to our colleagues in the scientific community. Maybe you will find in this special issue the encouragement to contribute to this collective task: to increase our knowledge on this issue and provide practical solutions to improve older adult's quality of life.

\section{Sabina Jelenc Krašovec, António Fragoso and Marta Gregorčič}

\section{REFERENCES}

Eurostat (2017). Adult participation in learning by gender (\%). Retrieved from http://ec.europa.eu/eurostat/tgm/table.do?tab=table\&init=1\&plugin=1\&lang.

Formosa, M., Jelenc Krašovec, S., \& Schmid-Hertha, B. (2015). Conclusion: Policy futures in older adult education and intergenerational learning. In B. Schmid-Hertha, S. Jelenc Krašovec \& M. Formosa (Eds.), Learning across generations in Europe. Contemporary issues in older adult education (pp. 203-212). Rotterdam: Sense Publishers. 
Fragoso, A., \& Formosa, M. (2014). Discussion and conclusion. In S. Jelenc Krašovec \& M. Radovan (Eds.), Older men learning in the community: European snapshots (pp. 99-107). Ljubljana: Ljubljana University Press, Faculty of Arts.

Fragoso, A., Ricardo, R., Tavares, N., \& Coelho, A. (2014). Shoulder to shoulder? Masculinities and informal learning in later life. Andragoška spoznanja (Studies in Adult Education and Learning), 20(3), 27-39.

Galea, R. C., \& Farrugia-Bonello, R. (2014). Older men learning through religious and political membership: Case studies from Malta. In S. Jelenc Krašovec \& M. Radovan (Eds.), Older men learning in the community: European snapshots (pp. 49-62). Ljubljana: Ljubljana University Press, Faculty of Arts.

Golding, B. G. (2011). Social, local and situated: Recent findings about the effectiveness of older men's informal learning in community contexts. Adult Education Quarterly, 6(2), 103-120.

Golding, B. (2012). Men's learning through community organisations: Evidence from an Australian study. In M. Bowl, R. Tobias, J. Leahy, G. Ferguson \& J. Gage (Eds.), Gender, Masculinities, and Lifelong Learning (pp. 134-146). Abingdon: Routledge.

Golding, B., Mark, R., \& Foley, A. (Eds.) (2014). Men learning through life. Leicester: NIACE.

Grenier, A. (2012). Transitions and the lifecourse. Bristol: The Polity Press.

Jelenc Krašovec, S., \& Radovan, M. (Eds.) (2014). Older men learning in the community: European snapshots. Ljubljana: Ljubljana University Press, Faculty of Arts.

Jelenc Krašovec, S., Radovan, M., Močilnikar, S., \& Šegula, S. (2014). Older men learning in urban and rural municipalities in Slovenia. In S. Jelenc Krašovec \& M. Radovan (Eds.), Older men learning in the community: European snapshots (pp. 79-98). Ljubljana: Ljubljana University Press, Faculty of Arts.

Kurantowicz, E. (2008). Community learning. Resources, actions and reflexivity of territorial communities. In Ewa Kurantowicz, António Fragoso, \& Emilio Lucio-Villegas (Eds.), Local in Global. Adult Learning and Community Development (pp. 55-60). Wrocław: University of Lower Silesia.

Loureiro, H., Ângelo, M., Silva, M., \& Pedreiro, A. (2015). How Portuguese families perceive transition to retirement. Revista de Enfermagem, IV(6), 45-54.

McGivney, V. (1999). Informal learning in the community. A trigger for change and development. Leicester: NIACE.

Quaresma, M. L. (2007). Envelhecer com futuro [Ageing with a future]. Fórum Sociológico, 17(2), $37-42$.

Ricardo, R., Tavares, N., Coelho, A., Lopes, H., \& Fragoso, A. (2014). Learning in informal spaces in the community: A case study from Southern Portugal. In S. Jelenc Krašovec \& M. Radovan (Eds.), Older men learning in the community: European snapshots (pp. 63-78). Ljubljana: Ljubljana University Press, Faculty of Arts.

Salgueiro, H., \& Lopes, M. (2010). A dinâmica da família que coabita e cuida de um idoso dependente [The dynamics of the family that lives with and takes care of an elderly dependent relative]. Revista Gaúcha de Enfermagem, 31(1), 26-32.

Smeaton, D., Barnes, H., \& Vegeris, S. (2016). Does retirement offer a ‘window of opportunity' for lifestyle change? Views from English workers on the cusp of retirement. Journal of Aging and Health, $16,1-20$.

Tambaum, T., \& Kuusk, H. (2014). Passing on skills and knowledge as part of learning for older men: Readiness and obstacles among older men in the municipality of Tartu. In S. Jelenc Krašovec \& M. Radovan (Eds.), Older men learning in the community: European snapshots (pp. 29-48). Ljubljana: Ljubljana University Press, Faculty of Arts. 